\title{
Leucine-Enhanced Essential Amino Acid Dietary Supplement
}

National Cancer Institute

\section{Source}

National Cancer Institute. Leucine-Enhanced Essential Amino Acid Dietary Supplement. NCI Thesaurus. Code C82357.

An orally bioavailable leucine enriched essential amino acid dietary supplement with potential anti-cachexia activity. Leucine-enhanced essential amino acid nutritional supplement may stimulate the mammalian target of rapamycin (mTOR) signaling pathway, which may promote protein synthesis in muscle cells. Although the exact mechanism by which leucine and other essential amino acids stimulate mTOR has yet to be fully elucidated, leucine may stimulate mT OR by inhibiting adenosine monophosphate protein kinase (AMPK), which negatively controls mTOR signaling. 